\title{
Species richness - energy relationships and dung beetle diversity across an aridity and trophic resource gradient
}

\author{
B. Power Tshikae*, Adrian L.V. Davis \& Clarke H. Scholtz \\ Scarab Research Unit, Dept of Zoology \& Entomology, University of Pretoria, Private Bag X20, Hatfield, \\ 0028 South Africa.
}

Running title: Increasing aridity, decreasing dung beetle diversity

\author{
B. Power Tshikae \\ Scarab Research Unit \\ Dept of Zoology \& Entomology \\ University of Pretoria \\ Private Bag X20 \\ Hatfield \\ 0028 South Africa \\ e-mail: bptshikae@zoology.up.ac.za \\ Tel.: +27 124203754 \\ Fax: +27 123625242
}




\section{ABSTRACT}

Understanding factors that drive species richness and turnover across ecological gradients is important for insect conservation planning. To this end, we studied species richness - energy relationships and regional versus local factors that influence dung beetle diversity in game reserves along an aridity and trophic resource gradient in the Botswana Kalahari. Dung beetle species richness, alpha diversity, and abundance declined with increasing aridity from northeast to southwest and differed significantly between dung types (pig, elephant, cattle, sheep) and carrion (chicken livers). Patterns of between-study area species richness on ruminant dung (cattle, sheep) differed to other bait types. Patterns of species richness between bait types in two southwest study areas differed from those in four areas to the northeast. Regional species turnover between study areas was higher than local turnover between bait types. Patterns of southwest to northeast species loss showed greater consistency than northeast to southwest losses from larger assemblages. Towards the southwest, similarity to northeast assemblages declined steeply as beta diversity increased. High beta diversity and low similarity at gradsect extremes resulted from two groups of species assemblages showing either northeast or southwest biogeographical centres. The findings are consistent with the energy hypothesis that indicates insect species richness in lower latitudes is indirectly limited by declining water variables, which drive reduced food resources (lower energy availability) represented, here, by restriction of large mammals dropping large dung types to the northeast and dominance of pellet dropping mammals in the arid southwest Kalahari. The influence of theoretical causal mechanisms is discussed.

\section{Keywords}

Aridity, Botswana Kalahari, diversity, dung beetle, ecotone, gradient, Scarabaeinae, species richness, trophic

\section{Introduction}

A global meta-study of regional ecological gradients indicates that rainfall, available energy, and waterenergy balance are the strongest influences on geographical patterns of change in species richness (Hawkins et al. 2003). The relative importance of these factors varies with latitude. In cool temperate regions, where energy availability is low, energy or water-energy balance were, generally, the strongest correlates with species richness. However, under the higher temperatures of warm temperate to tropical regions below latitudes $45^{\circ}-48^{\circ}$, there is a higher energy availability and, although energy would obviously remain important, its availability is limited by water variables so that species richness was most strongly correlated with rainfall. Thus, it may be hypothesized that towards the tropics increasing aridity leads to reduced resources (lower energy availability), leading to reduced species diversity. This is consistent with the suggestion of Hawkins et al. (2003) that for invertebrates, such as insects, species richness may be indirectly limited by water variables through their influence on plant productivity, which limits food availability. The present study examines how increasing aridity and diminishing trophic resources influence patterns of dung beetle diversity within game reserves across the Botswana Kalahari and discusses the 
possible response mechanisms (Evans et al. 2005) since understanding pattern and process at both landscape and local scale is important for conservation planning (Tscharntke et al. 2012).

An extensive literature confirms that patterns of species diversity across regional gradients are subject to both regional and local processes (e.g. Ricklefs 1987, Lobo et al. 2006, Mykrä et al. 2007) and it may be said that regional gradients result from changing local effects across regional space overlain by historical or regional influence on local patterns. Most regional gradients are characterized by a number of co-varying or co-linear factors that, in terms of responses by insects, may be of greater, equal, or lesser importance. By their very nature, aridity gradients may include further co-varying ecological influences besides changes in the availability of food and energy, such as more open vegetation physiognomy and increasing temperature. Interpretation of influences of aridity may also be confounded by ecologically influential, independent variation across space, such as differences in soil texture. Thus, assessing the relative importance of variables and the scale at which they operate is problematical as is assessing whether or not a significant correlation equates to causality in a relationship between environment and apparent biotic response.

The Botswana Kalahari comprises a northeast / southwest gradient in aridity and trophic resources that is ideal for studying interactions between the various regional and local influences on dung beetle diversity including relationships between species richness and energy availability. The regional gradient in declining annual rainfall ( $>600$ to $<200 \mathrm{~mm} \mathrm{p} / \mathrm{a}$ ) results in an opposing rainy season gradient of increasing average daily temperatures to the southwest that stems from reduced frequency of local rainfall events during summer when dung beetles were sampled (Tshikae et al. 2012a). Substantial rainfall is an initiator of high activity in dung beetles (Davis 1995, 2002) and with greater frequency of events might increase both the temporal diversity of activity patterns and opportunities for breeding, leading to greater abundance and increased species richness in the northeast. A parallel regional gradient in declining mammal species richness (>100 to <70) (Andrews and O'Brien 2000), density, and biomass (Tshikae et al. 2012a) results in reductions in energy availability through declines in dung type diversity, density of droppings, and amounts per dropping in arid southwestern localities (see Material and methods and Discussion). As a certain amount of dung type specialization has been recorded in dung beetles both in Botswana (Tshikae et al. 2008) and elsewhere (Fincher et al. 1970, Cambefort 1982), this might result in reduced opportunities for dung type specialization and loss of certain specialist species with increasing aridity (Tshikae et al. 2012b).

An analysis of species abundance structure at six study areas across the Botswana aridity gradient has identified two regional and six local components for dung-associated scarabaeine beetles, all but one representing $40-50 \%$ of total local variation (Tshikae 2011). The two regional components are correlated most strongly to annual rainfall, temperature during sampling, and an index derived from the density of 25 mammal species across the gradient (Tshikae et al. 2012a). One southwest-centred regional component declined in proportional contribution to the northeast whereas the other component was centred in the northeast and declined to the southwest. The point of intersection between regression lines, fitted to these components, supported a major boundary zone in the centre of the aridity gradient that was consistent with the ecoregion classification of Olson et al. (2001).

The current work uses various measures of diversity and similarity to examine regional and local patterns of species richness, diversity (gamma, beta, alpha), abundance, and behavioural group distribution, either side of the 
boundary zone that bisects the Botswana Kalahari aridity gradient. Particular emphasis is placed on co-varying patterns of species richness with increasing aridity and reduced trophic / energy resources. One aim of the study was to determine if species richness and diversity declined between study sites that are ranked according to declining rainfall, and if any insights might be gained from a joint consideration of regional patterns between study sites and local patterns between dung types. A second aim was to determine if patterns of richness and diversity between five bait types (four dung types plus carrion) might change across the gradient owing to regional changes in food / energy availability. This aim was based on the observation that two dung types are not found naturally at the dryer southwest end of the gradient owing to the absence of surface water except after substantial rain (Moyo et al. 1993, Penry 1994) causing the exclusion of mammal species that are both dependent on permanent water and drop the largest dung types (buffalo, elephants, zebra, rhinoceros) (Campbell 1973, Chamaillé-Jammes 2007). A third aim was to determine if patterns of species loss to the northeast and southwest of the boundary zone might reflect southwest and northeast biogeographical centres that have been demonstrated by Davis (1997) and Tshikae (2011). We also discussed other potential modifiers of patterns across the aridity and trophic gradient. These included variables independent of the gradients (landscape type - fossil lacustrine versus aeolian sands) as well as observed disturbances (livestock farming). These various empirical trends were discussed with regards to theoretical causal mechanisms for reduced species richness with reduced energy availability (Evans et al. 2005).

\section{Material and methods}

\subsection{Study region and geographical gradients}

The study was conducted from northeast to southwest across the deep sands of the Botswana Kalahari along an $1170 \mathrm{~km}$ gradient of increasing aridity (Fig. 1). Dung beetles were sampled from six study areas in three conserved regions; two areas per region and three study sites per area. These six study areas were in Chobe National Park (Chobe, Savuti), Central Kalahari Game Reserve (North CKGR, Khutse), and Kgalagadi Transfrontier Park (Mabuasehube, Transfrontier) (Fig. 1).

The northeast to southwest gradient in diminishing annual rainfall (Fig. 1), increasing summer temperatures, and decreasing annual temperatures (Scholes et al. 2002) is paralleled by changes in species richness and biomass of woody plants (O'Brien et al. 1998, Scholes et al. 2002). Strong shade cover occurred only in the woodland of Chobe in the extreme northeast whereas Savuti was characterized by dense but open shrubland (Tshikae 2011). Further to the southwest, cover density of shrubs was increasingly and significantly lower so that grassland became dominant. Cover density of grass was highly variable but was significantly lower only in the extreme southwest in Transfrontier (Tshikae 2011). Of four landscape types described for Botswana (Wit and de Bekker 1990, Fig. 2), two were represented across the gradsect, aeolian sands at Chobe in the northeast and at Khutse, Mabuasehube, and Transfrontier in the southwest, with fossil lacustrine deposits in the intervening Mababe (Savuti) and Makgadikgadi Depressions (North CKGR) in the northeast. However, analysis of soil texture at each of 
18 study sites showed no significant differences between landscape types as each comprised predominantly sand (adjusted figures: 97.1\% - 99.6\% sand) (Tshikae et al. 2012a).

Across the three conserved regions studied in the Botswana Kalahari, northeast to southwest declines in the density (4.61 to 1.32 to 1.93 individuals / $\mathrm{km}^{2}$ ) and combined biomass ( 5881.3 to 304.6 to $455.9 \mathrm{~kg} / \mathrm{km}^{2}$ ) of mammal species with a body size $>4 \mathrm{~kg}$ (Tshikae et al. 2012a) are consistent with the strong correlation shown between declines in mammal biomass with declines in rainfall and primary production in African savannas (Coe et al. 1976). The restriction to the northeast of large-bodied indigenous mammals that require permanent water sources (Campbell 1973, Chamaillé-Jammes 2007) results in cross-gradient changes in both the amounts and qualities of dung available in the natural ecosystem. According to the dung classification of Davis and Scholtz (2001) the northeast is characterized by four dung types, i.e. (1) large fibrous droppings of monogastric herbivores (elephant, rhinoceros, zebra); (2) large, moist pads of large ruminant herbivores (buffalo); (3) small collections of pellets dropped by other large to small herbivores (giraffe, antelope); and (4) small, highly nitrogenous droppings of many omnivores, scavengers and carnivores (baboon, lion). By contrast, only two dung types are dropped by the indigenous, mammal faunas of the central and southwest Kalahari, which are dominated by large to small, pelletdropping herbivores together with scavengers and carnivores (Tshikae et al. 2012a, 2012b).

\subsection{Sampling of dung beetles}

Five different bait types were used as attractants to sample dung beetles (certified disease-free dung: pig (omnivore), elephant (monogastric herbivore), cattle (pad-dropping ruminant herbivore), sheep (pellet-dropping ruminant herbivore); carrion: chicken livers). Other than elephant dung, the bait types acted as surrogates for natural carrion and the dung of wild animals, which are difficult to locate in the field. Elephant dung was collected fresh in Chobe National Park (Chobe, Savuti) or from Mokotodi Nature Reserve $\left(24.743^{\circ} \mathrm{S} 25.799^{\circ} \mathrm{E}\right)$ en route to central and southwestern study areas. The other dung types were obtained from the University of Pretoria experimental farm and, together with the chicken livers, were transported frozen in insulated, sealed containers to study areas where they were thawed before use.

At each of the 18 study sites, $20 \times 5 \mathrm{~L}$ pitfall traps (top diameter $=22 \mathrm{~cm}$, depth $=16 \mathrm{~cm}$ ) were emplaced in a $2 \times 10$ grid comprising a row either side of an access track. Each trap was separated by $50 \mathrm{~m}$, following the recommendations of Larsen and Forsyth (2005). Baits were placed on traps in the order of pig dung, cattle dung, elephant dung, carrion, and sheep dung, repeated four times. Dung baits comprised circa $250 \mathrm{mls}$ wrapped in thin cloth to exclude dung beetles but permit release of odours. Carrion baits comprised circa $100 \mathrm{mls}$ of cloth-wrapped chicken livers. Baits were supported at ground level over the centre of each trap using two strong wires.

In each study area, sampling was conducted over $48 \mathrm{~h}$ on a single occasion in December 2005 (Chobe, Savuti), January 2006 (North, CKGR, Khutse), or February 2006 (Mabuasehube, Transfrontier) following the shift in seasonal rainfall peaks from mid to late summer from the northeast to the southwest (Tshikae 2011). Sampling was conducted within 48 hours of substantial rainfall at all sites except North CKGR, which was sampled four days after rainfall. On sampling occasions, pitfall traps were baited or re-baited in the early morning and late afternoon to 
present fresh dung to both diurnal and nocturnal dung beetle species. Beetles were immobilized using water and a little detergent in the base of each trap. Samples were removed and stored in alcohol after each $24 \mathrm{~h}$ period. This method generated a total of 720 samples ( $=2$ days per sampling occasion x 6 study areas x 3 study sites per area $x 20$ traps per site - comprising 5 bait types $\mathrm{x} 4$ baits of each type per site). To reduce the complexity of results, data for days 1 and 2 were pooled before analyses were conducted.

\subsection{Analytical methods}

Relative completeness of the species record for each of five bait types in each of six study areas $(5 \times 6=$ 30) was predicted using EstimateS version 8.2 (Colwell, 2006). Estimates for each bait type were calculated from 50 randomizations of species data recorded over $48 \mathrm{~h}$ for 12 samples comprising four traps from each of three study sites per study area $(3 \times 4=12)$. Results are reported for two estimator methods that generated consistent results; Bootstrap and Michaelis-Menton.

Using a multiplicative method defined by Jost (2007), we partitioned gamma species richness and gamma exponential Shannon-Wiener diversity into independent expressions for alpha and beta diversity. To partition gamma species richness $\left({ }^{0} \mathrm{D}_{\gamma}\right)$ into "true" alpha $\left({ }^{0} \mathrm{D}_{\alpha}\right)$ and beta diversity $\left({ }^{0} \mathrm{D}_{\beta}\right)$, the following expressions were used:

${ }^{0} \mathrm{D}_{\gamma}=\mathrm{S}$

${ }^{0} \mathrm{D}_{\alpha}=(1 / \mathrm{N})\left(\mathrm{S}_{1}+\mathrm{S}_{2}+\ldots+\mathrm{S}_{\mathrm{j}}\right)$

${ }^{0} \mathrm{D}_{\beta}={ }^{0} \mathrm{D}_{\gamma} /{ }^{0} \mathrm{D}_{\alpha}$

where $\mathrm{S}$ is the total number of species in all sampling units, $\mathrm{S}_{\mathrm{j}}$ is the number of species per sampling unit, and $\mathrm{N}$ is the total number of sampling units. In the present study, the sampling units for analysis of spatial patterns were the six study areas and those for trophic patterns were the five bait types. To partition gamma exponential ShannonWiener diversity $\left({ }^{1} \mathrm{D}_{\gamma}\right)$ into "true" alpha $\left({ }^{1} \mathrm{D}_{\alpha}\right)$ and beta $\left({ }^{1} \mathrm{D}_{\beta}\right)$ diversity, the following expressions were used:

$$
\begin{aligned}
&{ }^{1} \mathrm{D}_{\gamma}=\exp \left[-\sum_{\mathrm{n}=1}^{\mathrm{s}}\left(p_{\mathrm{i}} \ln p_{\mathrm{i}}\right)\right] \\
&{ }^{1} \mathrm{D}_{\alpha}=\exp \left[-w_{1} \sum_{\mathrm{n}=1}^{\mathrm{s}}\left(p_{\mathrm{i} 1} \ln p_{\mathrm{i} 1}\right)+-w_{2} \sum_{\mathrm{n}=1}^{\mathrm{s}}\left(p_{\mathrm{i} 2} \ln p_{\mathrm{i} 2}\right)+\ldots .\right] \\
& w_{\mathrm{j}}=\operatorname{ind}_{\mathrm{j}} / \operatorname{ind}_{\mathrm{tot}} \\
&{ }^{1} \mathrm{D}_{\beta}=1 \mathrm{D}_{\gamma} / 1 \mathrm{D}_{\alpha}
\end{aligned}
$$

where $p$ is the decimal proportion of individuals of each species in all sampling units $\left({ }^{1} \mathrm{D}_{\gamma}\right)$, or each sampling unit $\left({ }^{1} \mathrm{D}_{\alpha}\right)$, and $w$ is the statistical weight contributed by each sampling unit to the total diversity. The statistical weight $(w)$ is calculated from the number of individuals in community $j\left(\right.$ ind $_{\mathrm{j}}$ ) divided by the total number of individuals $\left(\right.$ ind $\left._{\mathrm{tot}}\right)$.

Species richness, Shannon-Wiener diversity, abundance, and biomass of behavioural groups, were also compared using data recorded at the scale of individual traps after pooling data for days 1 and 2. Mean data were 
used to compare overall differences between study areas and between bait types. GLM factorial ANOVA and Tukey's HSD were used to determine significant differences between study areas and bait types. These data recorded at the scale of individual traps were also used to compare differences within study areas between bait types and differences within bait types between study areas. GLM one-way ANOVA and Tukey's HSD were used to determine significant differences.

Cluster analysis was used to examine overall similarity between study areas. The data matrix comprised six study areas by abundance data for 139 species standardized by conversion to proportions along 0-1 scale for each study area. The similarity matrix was calculated using the 1-Pearson $\mathrm{r}$ similarity coefficient and was subjected to clustering using unweighted pair-group average (StatSoft Inc. 2011).

Triangular data matrices were developed to compare pairs of study areas with regards to percentage similarity in both species composition and species abundance structure. Species composition was compared using the percentage disagreement measure of distance, dissimilarity coefficient (StatSoft Inc. 2011) which is expressed as distance $(x, y)=100\left(\sum\left|x_{i} \neq y_{i}\right| / I\right)$, in which $I$ is the total number of species and $\sum\left|x_{i} \neq y_{i}\right|$ is the number of instances in which a species is present in one study area and absent from the other. Results were expressed as percentage similarity $(100$ - distance $(x, y))$. Species abundance was compared using the Steinhaus similarity index: $\mathrm{S}=2 W /(A+B)$, in which $W$ is the sum of the smaller numbers in pairs of species abundance data converted to decimal proportions for each study area and in which $A(=1)$ and $B(=1)$ are the total proportional density of the two study areas (=2), that is, if $A=B=1, \mathrm{~S}=W$ (Legendre and Legendre 1983). The results are expressed as percentage similarity (S x 100).

Triangular data matrices were also developed using a recently defined method that partitions overall beta diversity $\left(\beta_{c c}\right)$ between pairs of study sites into species replacement $\left(\beta_{-3}\right)$ and species richness difference $\left(\beta_{\text {rich }}\right)$ components, i.e. $\beta_{\mathrm{cc}}=\beta_{-3}+\beta_{\text {rich }}$ (Carvalho et al. 2011). Overall beta diversity is expressed as: $\beta_{\mathrm{cc}}=(\mathrm{b}-\mathrm{c}) /(\mathrm{a}+\mathrm{b}+\mathrm{c})$, in which "a" is the number of species in common between two study sites, "b" is the number of species exclusive to the first study site, and "c" is the number of species exclusive to the second study site. This is equivalent to the Jaccard dissimilarity measure, which is equivalent to the $\beta_{\mathrm{cc}}$ complementarity measure of Colwell and Coddington (1994) in which " 0 " represents no difference in species composition and " 1 " represents no species in common between two study sites. The species replacement component is expressed as: $\beta_{-3}=2 \times((\min (b, c) /(a+b+c))$ in which $\min (b, c)$ is the smaller number represented by either $b$ or $c$. This is equivalent to a measure developed by Williams (1996) and modified by Cardoso et al. (2009). The richness difference component is expressed as: $\beta_{\text {rich }}=$ $|\mathrm{b}-\mathrm{c}| /(\mathrm{a}+\mathrm{b}+\mathrm{c})$ (Carvalho et al. 2011). Results are expressed graphically using data along the left vertical, basal horizontal and oblique axes.

Further triangular matrices were developed to examine species filtering or species loss from pairs of study areas in both northeasterly and southwesterly directions across the gradsect. One data matrix recorded the numbers of species represented in each study area that were not also recorded in those study areas lying to their southwest and the other matrix recorded the number of species in each area that were not also represented in areas lying to their northeast. Results are expressed graphically as above. 


\section{Results}

An overall total of 139 species was recorded comprising 123362 individuals with a Shannon-Wiener diversity of $H^{\prime}=3.26$, and an exponential Shannon-Wiener diversity of exp $\mathrm{H}^{\prime}=26.26$. The species record was relatively complete for the mid-summer sampling period on five bait types in six study areas $(5 \times 6=30)$ as greater than $85 \%$ of the species were recorded in all but three instances (Supplementary Table 1).

Whether measured as totals or means / trap, similar patterns were shown for overall species richness and Shannon-Wiener diversity (Tables 1, 2, Figs 3A-4D). Although species richness and diversity varied greatly between bait types, overall gamma (Tables 1, 2), overall alpha (Tables 1, 2) plus overall mean values (Figs 3A, 4C) showed a decline across the aridity gradient, with particularly low values for North CKGR representing an interruption in the principal trend. Although species richness varied greatly between study areas, overall gamma (Table 1), overall alpha (Table 1), plus overall mean values (Fig. 3B) showed declines from pig (omnivore) to elephant (monogastric herbivore) to ruminant herbivore dung (cattle, sheep) to carrion. However, patterns of overall diversity on bait types (gamma and mean values) showed various significant or non-significant declines from elephant to other dung types to carrion (Table 2, Fig. 3D) with a different pattern in the case of alpha diversity (Table 2 - sheep to cattle and elephant dung to pig dung and carrion). Both differences between study areas and bait types had a highly significant influence on mean species richness patterns (Fig. 3A) although study area was much the stronger significant influence on differences in mean Shannon-Wiener diversity (Fig. 4C).

Whether measured as totals or means / trap, roughly similar patterns were also shown by species richness and diversity for individual study area $\mathrm{x}$ bait type combinations (Tables 1, 2, Fig. 4). Two main patterns of response to bait type were shown within study areas, one representing higher values from carrion to pig and elephant dung with lower numbers on cattle and sheep dung (northeast and central study areas: Chobe, Savuti, North CKGR, with lower numbers on elephant dung in Khutse) and one representing higher numbers from carrion to pig dung then lower numbers on elephant dung and higher numbers on cattle to sheep dung (southwest study areas: Mabuasehube, Transfrontier) (Fig. 4A-4F). Two main patterns of response to bait type were also shown across study areas if ranked from mesic to arid climate (Fig. 4L), one for carrion, pig and elephant dung, and the other for ruminant herbivore dung (cattle pads, sheep pellets) (Figs 4G-4K). Local patterns also showed some individual variation, such as the relatively high species richness of the carrion fauna at Khutse.

Regional species turnover between study areas ( $\beta$ Bait) was much higher than local species turnover between bait types ( $\beta$ Area) (Table 2$)$. Across different areas on the same bait type ( $\beta$ Bait), beta diversity was greater than two but exceeded three in only one instance. Across different bait types within the same study area ( $\beta$ Area), beta diversity was greater than one but exceeded two in only one instance. Beta diversity showed a fair degree of similarity in values for both species richness and exponential Shannon-Wiener diversity (Tables 1,2$)$ despite the variation in gamma and alpha diversity. It was particularly uniform for exponential Shannon-Wiener diversity. Beta diversity values were consistently greater for species richness, which constitutes a presence or absence measure compared to Shannon-Wiener diversity, which measures relative abundance patterns between species. 
Overall patterns of mean abundance and mean biomass / trap (Figs 3E-3H) showed slightly different patterns to species richness and diversity (Figs 3A-3D). If ranked from mesic to arid climate, there were general declines to the southwest on aeolian sands interrupted by much lower values at study sites in areas dominated by lacustrine sands (Savuti, North CKGR) (Fig. 3E, 3G). Biomass of rollers (roll dung balls away from droppings) far exceeded that of other behavioural groups on aeolian sands whereas, on the lacustrine sands, they were slightly lower than that of tunnelers, kleptocoprids, and endocoprids (respectively, bury dung under droppings, use dung buried by other dung beetles, or breed within droppings). Both abundance and biomass were much greater on pig dung than on other bait types (Fig. 3F, 3H), which showed relatively small differences.

Assemblage structure in the southwest was grouped separately from that in the northeast (Fig. 5). For paired comparisons of study areas, similarities in species composition and species abundance structure declined steeply to the southwest in comparison with Chobe (left vertical axis) and steeply to the northeast in comparison with Transfrontier (basal horizontal axis - Tables 3A, 3B). Across the aridity gradient, comparisons between consecutive pairs of study areas showed slightly lower similarity in the centre (oblique axis - Tables 3A, 3B). Exceptionally low species richness in North CKGR was responsible for some extreme values in species loss and beta diversity (Fig. 6), for instance, the particularly high loss of species to the southwest from Savuti and high overall beta diversity values compared to Savuti and Khutse in paired comparison of consecutive study areas (Figs 6A, 6D). However, there was a clear decline in species replacement between consecutive pairs of study areas to the arid southwest (Fig. 6D). In paired comparisons between end points and other study areas in sequence along the gradsect, there were steep gradients in loss of species to the southwest from the more species rich northeast assemblages whereas species loss to the northeast followed more shallow gradients (Figs 6B, 6C). Loss to northeast study areas from southwest study areas was a uniform 24-26 species (Figs 6B, 6C, Supplementary Table 3) whereas the opposite was more variable. Complementary patterns were shown by beta diversity and species richness differences, which increased to the southwest (compared to Chobe) or to the northeast (compared to Transfrontier). Compared to Transfrontier, species replacement also increased to the northeast but it occurred at a constant rate across the northeast / southwest gradient compared to Chobe.

\section{Discussion}

\subsection{Empirical trends and theoretical mechanisms influencing species richness variability}

Declines in insect species richness across lower latitude aridity gradients are considered to be indirectly driven by the influence of declining rainfall on declining primary productivity (Hawkins et al. 2003), which equates to the reduced availability of energy. Previously published studies on plant and animal responses to the aridity and trophic resource gradient of the Botswana Kalahari (O’Brien et al. 1998, Andrews and O'Brien 2000) suggest that it is an ideal platform for the empirical examination of species richness - energy relationships along an energy gradient

across a range edge (Olson et al 2001, Tshikae 2011). An understanding of the processes that define declines in 
species richness and diversity, as well as changes in dung beetle trophic associations, is useful for conservation planning.

Although nine overlapping causal mechanisms have been postulated for the positive association between species richness and energy availability at the macro-scale, there is insufficient evidence to identify dominant influences (Evans et al. 2005). The classic explanation is that abundance and diversity of resources is greater in higher energy areas thus supporting greater population densities, greater numbers of species, and reduced extinction rates (Wright 1983). However, owing to the greater complexity of resources and biotic interactions in higher energy areas, other causal mechanisms could play a part, including increased complexity of biotic interactions, increased niche specialization, increased physiological suitability for more species, and increased speciation rates (Evans et al. 2005, Evans \& Gaston 2005).

\subsection{Empirical cross-Kalahari trends in primary producers and mammal primary and secondary consumers}

From northeast to southwest across the Botswana Kalahari, the steep decline in rainfall is paralleled by a steep decline in woody plant species richness ( $>200$ to $<15$ - O'Brien et al. 1998), biomass (mean 36.1 to 13.8 units - Scholes et al. 2002), and tree density (968 to 181 per ha - Caylor et al. 2003) that would represent a great reduction in primary productivity. This is paralleled by declining mammal species richness ( $>100$ to $<70$ - Andrews and O'Brien 2000) and a 12.9 times decrease in biomass per unit area (see Material and methods) that parallels the loss of very large-bodied, primary consumers (Campbell 1973, Chamaillé-Jammes 2007) dropping the largest dung types (Tshikae 2011), and which would be consistent with the well-known relationship between rainfall, mammal biomass, and primary productivity (Coe et al. 1976). Although small numbers of eland ( $840 \mathrm{~kg}$ ) have been observed in the southwest (Ministry of Environment, Wildlife and Tourism 2004), indigenous mammal assemblages of the southwest are dominated by herbivores (primary consumers) with a body size no greater than $250 \mathrm{~kg}$ and predators or scavengers (secondary consumers) with a body size no greater than $225 \mathrm{~kg}$ (Wallgren et al. 2008), all of which drop either collections of dung pellets (diameter, 1-2 cm) or small elongate droppings (breadth $\mathrm{x}$ length, $2 \mathrm{~cm} \times \mathrm{x}$ 5-15 cm) (Liebenberg 1990). Although no measurements have been made, the loss of elephants (body size, $1725 \mathrm{~kg}$; dung bolus diameter, $15-20 \mathrm{~cm})$, zebra $(313 \mathrm{~kg} ; 5 \mathrm{~cm})$ and buffalo $(450 \mathrm{~kg} ; 15 \mathrm{~cm})$ to the southwest would represent great reductions in the amounts of food available to dung beetles (secondary consumers) as well as reduction in diversity of dung type resources according to the classification of Davis \& Scholtz (2001) (see Material and methods). Perhaps reflecting their dependence on permanent water sources (Campbell 1973, Chamaillé-Jammes 2007), the water content of larger dung types dropped by zebra, elephant, and buffalo (75.2 to $77.6 \%)$ is greater than that of pellet droppings (50.4 to 54.5\% - impala, giraffe) (Paetel 2001).

\subsection{Empirical cross-Kalahari trends in dung beetles}

Unpublished collection records from southern African museums suggest that the 139 species of dung beetles recorded across the gradsect represent the majority known from the deep Kalahari sands of Botswana. 
Although one known Kalahari sand specialist was not recorded (Copris inhalatus ssp. perturbator Péringuey), of those species that were captured, several were not formerly known to the authors and some may represent undescribed species.

Species richness and diversity of dung beetles varied at both regional and local scales and were strongly influenced by both spatial and trophic factors. Three interacting influences may primarily account for the differences. These are (1) declines across the aridity gradient; (2) differences in patterns of trophic association that are responsible for both local (trophic) and regional (spatial) trends; and (3) patterns of turnover that stem, especially, from differences between species compositions of heterogeneous mesic and less heterogeneous arid biogeographical centres across a boundary zone. These have developed over an historical timescale. In current assemblages, the greater species richness in the northeast probably results from the greater heterogeneity of resources that are known to influence dung beetle activity such as vegetation physiognomy and soil type (Davis 1996), amount, diversity and density of dung (Lumaret et al. 1992, Lobo et al. 2006), as well as incidence, amount, and frequency of rainfall events (Davis 2002). The decline in species richness to the southwest would be driven by regional reductions in these ecologically important factors, including increasingly lower rainfall with fewer rainfall events leading to higher summer temperatures; lower dung type diversity, density, and amounts of dung; reduced habitat heterogeneity, and differences in bait type association shown by the local dung beetle assemblages. These factors co-vary to drive both regional and local trends in species richness and diversity (Tshikae et al. 2012a, 2012b). In the present study, ranking of influential variables showed that the relative influence of rainfall (1.00 on a 0-1 scale), temperature (1.00) and mammal density (0.73-0.89) far outweighed those of soil texture (0.39-0.46; entirely sand) and shade cover from woody vegetation (0.40-0.41; strong tree cover only in Chobe) (Tshikae et al. 2012a).

Cross-Kalahari geographical trends in species richness, turnover, Shannon-Wiener diversity, abundance, biomass, and similarity between dung beetle assemblages are consistent with analyses that show clear differences in their biogeographical composition, species abundance structure, and trophic associations between the mesic northeast and the arid southwest (Tshikae 2011, Tshikae et al. 2012a, 2012b). Although species richness declined, overall, from northeast to southwest, as in other studies of animal distribution across the Kalahari (Barker 1993, Andrews and O'Brien 2000), patterns of decline in species richness diversity abundance and biomass were uneven across space owing to bimodality either side of the central Kalahari transitional zone. There were also changes in the pattern of association with ruminant herbivore dung types between the mesic northeast and the most arid part of the southwest Kalahari (Kgalagadi Transfrontier Park). This represented a change from the pattern shown by assemblages to the northeast (Fig. 4, n.b. pattern in Chobe may be an artifact due to capture of beetles flying to elephant dung dropped next to a sheep dung-baited trap) and may reflect the loss of some dung types and their specialist fauna to the southwest, the large-scale replacement of northeast savanna species by less abundant arid centred species adapted to reduced frequency of rain and drier dung types, and a shift in associations so that greatest numbers of species were recorded on dung types dropped in small quantities (carnivore faeces, small ruminant herbivore pellets) that are characteristic of the natural mammal fauna of this region. Furthermore, the experimental presentation of dung types not found naturally in the southwest, particularly elephant dung, showed that it was 
colonized by the local dung beetle fauna but that the overall pattern of resource partitioning differed to that in the northeast (Tshikae et al. 2012b)

Cross-tabulation of results for species richness and diversity on five food types across the aridity gradient of the Botswana Kalahari shows that differences between bait types within each study area were consistently less variable than those between study areas on each bait type. As beta diversity values generated by the multiplicative method correspond to the number of distinct communities within the measured gamma diversity (Jost 2007), the dominance of values lying between one and two for distribution between bait types within each study areas ( $\beta$ Bait) might be a response to the strong separation but appreciable overlap between dung and carrion assemblages (Tshikae 2011). Although some of the species attracted to carrion and different dung types were relative specialists (Tshikae et al. 2012b), many were more generalist in their associations and responsible for reducing beta diversity values. Most of the beta diversity values for distribution between study areas on each dung bait type (BArea) lie between two to three, which is consistent with the distinctly different biogeographical groups and different patterns of resource partitioning demonstrated for dung-associated beetles across the aridity gradient (Tshikae 2011, Tshikae et al. 2012b).

Although beta diversity has been used to identify transition zones between regions (Williams 1996), of the various methods used here, the clearest separation into two regional biogeographical groups was demonstrated by cluster analysis of the relative abundances of 139 species between the six study areas. However, paired comparisons between study sites have demonstrated various patterns of decreasing faunal similarity and increasingly higher species turnover across the aridity gradient. Simple counts of species lost to the northeast and southwest parallel the progression from a northeastern biogeographical centre to another centred in the southwest (Tshikae 2011). The similarity in numbers lost to the northeast (24-26 in eight paired comparisons) presumably represent Kalahari centred species whereas the larger though more variable number lost to the southwest (36-63 in eight paired comparisons) presumably represent more mesic savanna-centred species. Dividing overall beta diversity $\left(\beta_{\mathrm{cc}}\right)$ into components reduces the slope of numerical gradients and provides greater insight into contributory factors. In some cases, progressions across the aridity gradient shown by species replacement $\left(\beta_{-3}\right)$ and richness differences $\left(\beta_{\text {rich }}\right)$ are uneven due to the unexpected low numbers in North CKGR.

\subsection{Theoretical mechanisms influencing cross-Kalahari species richness variability}

In line with theoretical mechanisms that possibly influence species richness across energy gradients (Evans et al. 2005), patterns in the Kalahari are discussed in terms of dung beetle population size versus species richness, resource availability versus niche width, and physiological tolerance versus range limitation. As there were uneven declines in richness across the Kalahari aridity gradient, we also consider the possible influence of energyindependent habitat factors such as soil texture. Furthermore, as mammal biomass was lowest in the central Kalahari (Tshikae et al. 2012a), it is probable that the availability of energy from carrion and dung did not decline uniformly with increasing aridity. 
Greater availability of energy has been hypothesized to increase resource abundance, which supports greater population sizes and greater species richness (Wright 1983). Overall decline in abundance with increasing aridity on aeolian sands (NE: Chobe; SW: Khutse, Mabuasehube, Transfrontier) is followed by a similar pattern of decline in species richness. This gradual decline is interrupted by a sharp dip in abundance and biomass on lacustrine sands (NE: Savuti, North CKGR) with a reversal in dominance of behavioural groups from higher roller biomass on aeolian sands to higher tunneler biomass on lacustrine sands. Furthermore, on the lacustrine sands of Savuti where energy availability from dung would be high, abundance was as low as on aeolian sands in Transfrontier where energy availability would be much lower. Even so, overall species richness was significantly higher at Savuti than at the arid extreme in Transfrontier although significant differences were recorded only on those individual baits that did not occur naturally in the southwest (elephant, cattle). Although study sites in North CKGR were on isolated parabolic dunes, they lay within the edge of a large expanse of lacustrine soils comprising the Mkgadigadi Depression. Both abundance and species richness were significantly lower than in all other study areas and may reflect particularly low mammal density whereas changes in proportional representation of behavioral groups may stem from undetected differences in soil texture. These patterns indicate that to effectively study species richness - energy relationships, it is essential to standardize habitat variables across a gradient.

It has been hypothesized that increases in abundance and diversity of resources in areas of higher productivity favour niche specialization and reduced niche width, thus reducing competitive exclusion and supporting greater species richness (Evans et al. 2005). For dung beetles, availability of trophic resources did not vary in parallel across the Kalahari since large monogastric and ruminant herbivores were absent from conserved southwestern regions whereas densities of smaller bodied pellet-dropping herbivores decreased to the northeast (Tshikae et al. 2012a). Furthermore, trophic niche widths of dung beetle species did not narrow from the lower energy, arid southwest to the higher energy, mesic northeast. In fact, at three different abundance levels of species exclusion, mean niche width ( 0 to 1 , narrow to wide) was much narrower in study areas either side of the central Kalahari transition zone (Khutse: 0.19-0.22; not consistent at North CKGR: 0.22-0.35 - Tshikae et al. 2012b) where energy availability for dung beetles would be lower than at either the arid or mesic end points based on density of mammal biomass. At these extremes, mean niche widths were similar (0.34-0.41) despite lower to higher energy availability and lower to higher species richness from southwest to northeast. This suggests that, in this case, niche width is independent of factors influencing trophic resource availability or species richness.

It has been hypothesized that there are greater numbers of species in higher energy areas since climatic conditions are physiologically more tolerable than in lower energy areas (Kerr et al. 1998). Species occurring in lower energy areas would be exposed to greater climatic extremes and would show a wider range of tolerances (Evans et al. 2005). Conditions in areas outside of a species physiological tolerance would act to limit its range. In the central Kalahari, a transitional region between North CKGR and Khutse (Olson et al. 2001) is supported by statistical analyses of dung beetle species abundance structure, biogeographical composition, and trophic associations (Tshikae 2011) suggesting that this region constitutes a range edge between higher and lower energy areas for many of the 139 dung beetle species that were recorded. Of these species, 64 species were restricted to the northeast and 26 to the southwest. Greater than $80 \%$ of the abundance of a further 15 species were biased to 
northeastern occurrence and 17 to the southwest whereas only 17 were more equitably shared between regions. Climate rather than energy availability may be more important in defining the transitional zone since as it lay in the central Kalahari rather than further to the northeast in North CKGR where the trend to lower mammal density and, therefore, lower food availability commenced. It is unknown if southwestern dung beetle endemics show wider physiological tolerances. However, dung beetles are most active immediately after rainfall (Davis 1995, 2002), which has the effect of reducing temperatures. Lower abundance of beetles active under the more extreme temperatures of droughts suggests that, as fossorial insects, many avoid unfavourable conditions by remaining buried in the soil where temperatures are more equitable. Thus, although greater species richness is strongly biased to the higher energy region, behavioural adaptation might be more important than heightened physiological tolerance for many of the southwestern endemics.

\subsection{Natural variability vs habitat modification and implications for conservation}

Although the present data were recorded in conserved regions, human settlement and cattle ranching have modified some of the intervening areas (Wallgren et al. 2009). The provision of borehole water on farms (Perkins 1996) adjacent to southwestern reserves now permits the support of large ruminant (cattle) and monogastric herbivores (horse, donkey) (Wallgren et al. 2008) dropping dung types formerly absent from the southwest. Analysis of mammal census data yielded four groups centred on wildlife management areas or a village complex $\left(24^{\circ} 04^{\prime} \mathrm{S}\right.$ $21^{\circ} 40^{\prime} \mathrm{E}$ ) north of Mabuasehube (Wallgren et al. 2008). Two were dominated by domestic livestock and were associated with villages either distant from or close to pans. The other two were both distant from villages and were dominated by either indigenous mammals distant from pans or by ostriches close to pans. The indigenous mammal group included only $0.2 \%$ domestic livestock. Furthermore, greater than $70 \%$ of domestic livestock were observed within $25 \mathrm{~km}$ of villages and few unattended livestock were observed more than $25 \mathrm{~km}$ away from villages. It is probable that development had little influence on the present results since only limited incursions into central and southwestern reserves have been recorded by aerial mammal census (Ministry of Wildlife, Environment and Tourism 2004) and the nearest cattle ranching to central Kalahari study areas were about $30 \mathrm{~km}$ away from North CKGR and about $20 \mathrm{~km}$ away from Khutse. However, it is advisable that further work should be done in order to gauge the effect of development of the Kalahari for cattle ranching and its possible effect on conservation in the adjoining reserves.

\subsection{Conclusions}

Increasing dissimilarity between assemblages across the aridity gradient was reflected by high species turnover with differing patterns of species loss from northeast and southwest biogeographical centres. Patterns of richness and diversity also differed between arid southwest and mesic northeast study sites, and between ruminant herbivore and other dung types. There were similar regional declines in species richness and diversity on each of five food types across the aridity gradient despite local differences in species richness between food types. 
Interruptions in the slopes of decline may reflect particularly low local mammal density in North CKGR and differences in soil texture between aeolian sands and lacustrine sands in both Savuti and North CKGR. Despite this uneven progression, declines in abundance and species richness across the Kalahari aridity gradient were consistent with the hypothesis that water variables limit the availability of food energy by reducing primary productivity, thus favouring small bodied herbivores and their predators that void low moisture pellets or small cohesive droppings.

\section{Acknowledgements}

We thank the GEF-Small Grant Programme and the University of Pretoria for funding the research. Thanks are also due to the government of Botswana for giving permission to do research in Chobe National Park, CKGR and Kgalagadi Transfrontier Park. We also thank the Park staff for providing necessary information and camping facilities, members of the Scarab Research Group for support in field trips, and McDonald Mokhatla for sorting the samples.

\section{References}

Andrews, P., O’Brien, E.M., 2000. Climate, vegetation, and predictable gradients in mammal species richness in southern Africa. J. Zool. 251, 205-231.

Barker, J.F., 1993. Distribution patterns of Kalahari Desert Acridoidea (Orthoptera: Caelifera). Afr. Entomol. 1, 8191.

Cambefort, Y., 1982. Les coléoptères Scarabaeidae s. str. de Lamto (Côte d'Ivoire): structure des peuplements et rôle dans l'écosystème. Ann. Soc. Entomol. Fr. 18, 433-459.

Campbell, A.C., 1973. The national park and reserve system in Botswana. Biol. Conserv. 5, 7-14.

Cardoso, P. Borges, P.A.V., Veech, J.A., 2009. Testing the performance of beta diversity measures based on incidence data: the robustness to undersampling. Divers. Distrib. 15, 1081-1090.

Carvalho, J.C., Cardoso, P., Gomes, P., 2011. Determining the relative roles of species replacement and species richness differences in generating beta-diversity patterns. Global Ecol. Biogeogr. 21, 760-771.

Caylor, K.K., Shugart, H.H., Dowty, P.R., Smith, T.M., 2003. Tree spacing along the Kalahari transect in southern Africa. J. Arid Environ. 54, 289-296.

Chamaillé-Jammes, S., Valeix, M., Fritz, H., 2007. Managing heterogeneity in elephant distribution: interactions between elephant population density and surface-water availability. J. Appl. Ecol. 44, 625-633.

Coe, M.J., Cummings, D.H., Phillipson, J., 1976. Biomass and production of large African herbivores in relation to rainfall and primary production. Oecologia 22, 341-354.

Colwell, R.K., Coddington, J.A., 1994. Estimating terrestrial biodiversity through extrapolation. Philos. T. Roy. Soc. B 345, 101-118.

Colwell, R.K., 2006. EstimateS: Statistical estimation of species richness and shared species from samples. Version 8.2. Persistent URL at http://purl.oclc.org/estimates 
Davis, A.L.V., 1995. Daily weather variation and temporal dynamics in an Afrotropical dung beetle community (Coleoptera: Scarabaeidae). Acta Oecol. 16, 641-656.

Davis, A L.V., 1996. Habitat associations in a South African, summer rainfall, dung beetle community (Coleoptera: Scarabaeidae, Aphodiidae, Staphylinidae, Histeridae, Hydrophilidae). Pedobiologia 40, 260-280.

Davis, A.L.V., 1997. Climatic and biogeographical associations of southern African dung beetles (Coleoptera: Scarabaeidae s. str.). Afr. J. Ecol. 35, 10-38.

Davis, A.L.V., 2002. Dung beetle diversity in South Africa: influential factors, conservation status, data inadequacies, and survey design. Afr. Entomol. 10, 53-65.

Davis, A.L.V., Scholtz, C.H., 2001. Historical versus ecological factors influencing global patterns of scarabaeine dung beetle diversity. Divers. Distrib. 7, 161-174.

Evans, K.L., Gaston, K.J., 2005. Can the evolutionary-rates hypothesis explain species-energy relationships? Funct. Ecol. 19, 899-915.

Evans, K.L., Warren, P.H., Gaston, K.J., 2005. Species-energy relationships at the macroecological scale: a review of the mechanisms. Biol. Rev. 80, 1-25.

Fincher, G.T., Stewart, T.B., Davis, R., 1970. Attraction of coprophagous beetles to feces of various animals. J. Parasit. 56, 378-383.

Hawkins, B.A., Field, R., Cornell, H.V., Currie, D.J., Guégan, J.-F., Kaufman, D.M., Kerr, J.T., Mittelbach, G.G., Oberdorff, T., O'Brien, E.M, Porter, E.E., Turner, J.R.G., 2003. Energy, water, and broad-scale geographic patterns of species richness. Ecology 84, 3105-3117.

Jost, L., 2007. Partitioning diversity into independent alpha and beta components. Ecology 88, 2427-2439.

Kerr, J.T., Vincent, R., Currie, D.J., 1998. Lepidopteran richness patterns in North America. Ecoscience 5, 448-553.

Larsen, T.H., Forsyth, A., 2005. Trap spacing and transect design for dung beetle biodiversity studies. Biotropica 37, $322-325$.

Legendre, L., Legendre, P., 1983. Numerical ecology. Elsevier, Amsterdam.

Liebenberg, L., 1990. A field guide to the animal tracks of southern Africa. David Philip Publishers, Cape Town and Johannesburg.

Lobo, J.M., Hortal, J., Cabrero-Sañudo, F.J., 2006. Regional and local influence of grazing activity on the diversity of a semi-arid dung beetle community. Divers. Distrib. 12, 111-123.

Lumaret, J.P., Kadiri, N., Bertrand, M., 1992. Changes in resources: consequences for the dynamics of dung beetle communities. J. Appl. Ecol. 29, 349-356.

Ministry of Environment, Wildlife and Tourism, 2004. Department of Wildlife and National Parks census report. Government Press, Gaborone, Botswana.

Moyo, S., O'Keefe, P., Sill, M., 1993. The Southern African Environment: Profiles of the SADC Countries. Earthscan Publications Ltd., London.

Mykrä, H., Heino, J., Muotka, T., 2007. Scale-related patterns in the spatial and environmental components of stream macroinvertebrate assemblage variation. Global Ecol. Biogeogr. 16, 149-159. 
O’Brien, E.M., Whittaker, R.J., Field, R., 1998. Climate and woody plant diversity in southern Africa: relationships at species, genus and family levels. Ecography, 21, 495-509.

Olson, D.M., Dinerstein, E., Wikramanayake, E.D., Burgess, N.D., Powell, G.V.N., Underwood, E.C., d'Amico, J.A., Itoua, I., Strand, H.E., Morrison, J.C., Loucks, C.J., Allnutt, T.F., Ricketts, T.H., Kura, Y., Lamoreux, J.F., Wettengel, W.W., Hedao, P., Kassem, K.R., 2001. Terrestrial ecoregions of the world: a new map of life on earth. Bioscience 51, 933-938.

Paetel, C., 2001. Is there really a strong "follow-up" evolutionary background in herbivore dung utilisation by Scarabaeinae? Mitt. Mus. Nat. Berl. Zool. Reihe 77, 229-235.

Penry, H., 1994. Bird Atlas of Botswana. University of Natal Press, Pietermaritzberg, South Africa.

Perkins, J.S., 1996. Botswana: fencing out the equity issue. Cattleposts and cattle ranching in the Kalahari Desert. J. Arid Environ. 33, 503-517.

Ricklefs, R.E., 1987. Community diversity: Relative roles of local and regional processes. Science 235, 167-171.

Scholes, R.J., Dowty, P.R., Caylor, K., Parsons, D.A.B., Frost, P.G.H., Shugart, H.H., 2002. Trends in savanna structure and composition along an aridity gradient in the Kalahari. J. Veg. Sci. 13, 419-428.

StatSoft Inc. (2011) STATISTICA (data analysis software system), version 10. www.statsoft.com.

Tscharntke, T., Tylianakis, J.M., Rand, T.A., Didham, R.K., Fahrig, L., Batáry, P., Bengtsson, J., Clough, Y., Crist, T.O., Dormann, C.F., Ewers, R.M., Fründ, J., Holt, R.D., Holzschuh, A., Klein, A.M., Kleijn, D., Kremen, C., Landis, D.A., Laurance, W., Lindenmayer, D., Scherber, C., Sodhi, M., Steffan-Dewenter, I., Thies, C., van der Putten, W.H., Westphal, C., 2012. Landscape moderation of biodiversity patterns and processes eight hypotheses. Biol. Rev. 87, 661-685.

Tshikae, B.P., 2011. Local and regional factors influencing dung beetle assemblage structure across an environmental gradient in Botswana. Ph.D. thesis, University of Pretoria, South Africa. [Online] http://upetd.up.ac.za/thesis/available/etd-10192011-133622/

Tshikae, B.P., Davis, A.L.V., Scholtz, C.H., 2008. Trophic associations of a dung beetle assemblage (Scarabaeidae: Scarabaeinae) in a woodland savanna of Botswana. Environ. Entomol. 37, 431-441.

Tshikae, B.P., Davis, A.L.V., Scholtz, C.H., 2012a. Dung beetle assemblage structure across the aridity and trophic resource gradient of the Botswana Kalahari: patterns and drivers at regional and local scales. J. Insect Conserv. (in press).

Tshikae, B.P., Davis, A.L.V., Scholtz, C.H., 2012b. Does an aridity and trophic resource gradient drive patterns of dung beetle food selection across the Botswana Kalahari? Ecol. Entomol. (in press).

Wallgren, M., Skarpe, C., Bergström, R., Danell, K., Bergström, A., Jakobsson, T., Karlsson, K., Strand, T., 2009. Influence of land use on the abundance of wildlife and livestock in the Kalahari, Botswana. J. Arid Environ. 73, 314-321.

Wallgren, M., Skarpe, C., Bergström, R., Kjell, D., Granlund, L., Bergström, A., 2008. Mammal community structure in relation to disturbance and resource gradients in southern Africa. Afr. J. Ecol. 47, 20-31.

Williams, P.H., 1996. Mapping variations in the strength and breadth of biogeographic transition zones using species turnover. P. Roy. Soc. Lond. B Bio. 263, 579-588. 
Wit, P.V., de Bekker, R.P., 1990. Land systems map of the Republic of Botswana. Soil mapping and advisory services project AG:DP/BOT/85/011. FAO Ministry of Agriculture, Gaborone. Accessed 25.02.2012 at http://eusoils.jrc.ec.europa.eu/esdb_archive/eudasm/africa/lists/cbw.htm

Wright, D.H., 1983. Species-energy theory, an extension of species-area theory. Oikos 41, 496-506. 
Table 1

Multiplicative partitioning of species richness $\left({ }^{\circ} \mathrm{D}\right)$ for study areas (Area $=$ species richness within the same study area across different baits) and bait type (Bait $=$ species richness on the same bait type across different study areas). Study areas are ranked from mesic to arid climate.

\begin{tabular}{|c|c|c|c|c|c|c|c|c|}
\hline $\begin{array}{l}\text { Bait Type> } \\
\text { Study Area }\end{array}$ & $\begin{array}{c}\text { Carrion } \\
{ }^{0} \mathrm{D}\end{array}$ & $\begin{array}{l}\text { Pig } \\
{ }^{0} \mathrm{D}\end{array}$ & $\begin{array}{l}\text { Elephant } \\
{ }^{0} \mathrm{D}\end{array}$ & $\begin{array}{c}\text { Cattle } \\
{ }^{0} \mathrm{D}\end{array}$ & $\begin{array}{l}\text { Sheep } \\
{ }^{0} \mathrm{D}\end{array}$ & $\begin{array}{c}\gamma \text { Area } \\
{ }^{0} \mathrm{D}\end{array}$ & $\begin{array}{c}\alpha \text { Area } \\
{ }^{0} \mathrm{D}\end{array}$ & $\begin{array}{c}\beta \text { Area } \\
{ }^{0} \mathrm{D}\end{array}$ \\
\hline Chobe & 33 & 53 & 47 & 36 & 52 & 71 & 44.0 & 1.61 \\
\hline Savuti & 25 & 45 & 50 & 48 & 35 & 77 & 40.6 & 1.90 \\
\hline North CKGR & 14 & 32 & 27 & 19 & 12 & 48 & 20.8 & 2.31 \\
\hline Khutse & 28 & 51 & 46 & 25 & 22 & 59 & 34.4 & 1.72 \\
\hline Mabuasehube & 19 & 32 & 28 & 21 & 38 & 45 & 27.8 & 1.62 \\
\hline Transfrontier & 14 & 31 & 23 & 29 & 31 & 40 & 25.6 & 1.56 \\
\hline$\gamma$ Bait & 59 & 106 & 101 & 88 & 98 & & & \\
\hline$\alpha$ Bait & 22.2 & 40.5 & 34.7 & 31.7 & 31.7 & & & \\
\hline$\beta$ Bait & 2.66 & 2.62 & 2.91 & 2.78 & 3.10 & & & \\
\hline
\end{tabular}

Table 2

Multiplicative partitioning of exponential Shannon-Wiener diversity $\left({ }^{1} \mathrm{D}\right)$ for study areas (Area = diversity within the same study area across different baits) and bait type (Bait = diversity on the same bait type across different study areas). Study areas are ranked from mesic to arid climate.

\begin{tabular}{|c|c|c|c|c|c|c|c|c|}
\hline $\begin{array}{l}\text { Bait Type> } \\
\text { Study Area }\end{array}$ & $\begin{array}{l}\text { Carrion } \\
{ }^{1} \mathrm{D}\end{array}$ & $\begin{array}{l}\text { Pig } \\
{ }^{1} \mathrm{D}\end{array}$ & $\begin{array}{l}\text { Elephant } \\
{ }^{1} \mathrm{D}\end{array}$ & $\begin{array}{l}\text { Cattle } \\
{ }^{1} \mathrm{D}\end{array}$ & $\begin{array}{l}\text { Sheep } \\
{ }^{1} \mathrm{D}\end{array}$ & $\begin{array}{c}\gamma \text { Area } \\
{ }^{1} \mathrm{D}\end{array}$ & $\begin{array}{c}\alpha \text { Area } \\
{ }^{1} \mathrm{D}\end{array}$ & $\begin{array}{l}\beta \text { Area } \\
{ }^{1} \mathrm{D}\end{array}$ \\
\hline Chobe & 15.89 & 8.46 & 13.45 & 12.67 & 13.21 & 12.44 & 10.54 & 1.18 \\
\hline Savuti & 6.64 & 8.14 & 9.89 & 11.08 & 11.98 & 12.47 & 9.27 & 1.35 \\
\hline North CKGR & 3.93 & 4.37 & 5.47 & 5.04 & 4.40 & 5.61 & 4.75 & 1.18 \\
\hline Khutse & 9.55 & 9.64 & 10.80 & 7.72 & 3.50 & 11.69 & 9.37 & 1.25 \\
\hline Mabuasehube & 5.32 & 8.71 & 7.63 & 8.11 & 9.18 & 10.52 & 8.54 & 1.23 \\
\hline Transfrontier & 3.56 & 7.06 & 6.82 & 8.47 & 9.49 & 9.73 & 7.81 & 1.25 \\
\hline$\gamma$ Bait & 17.44 & 20.72 & 24.62 & 22.71 & 23.27 & & & \\
\hline aBait & 8.63 & 8.31 & 9.81 & 9.52 & 10.54 & & & \\
\hline$\beta$ Bait & 2.02 & 2.49 & 2.51 & 2.39 & 2.21 & & & \\
\hline
\end{tabular}


Table 3

Triangular matrices comparing proportional similarity of species composition and species abundance structure between pairs of study sites.

A. Species composition (100 - Distance (x, y))

\begin{tabular}{lrrrrrr}
\hline Study area & Chobe & Savuti & CKGR & Khutse & Mabua. Transf. \\
\hline Chobe & 100.0 & & & & & \\
Savuti & 49.0 & 100.0 & & & & \\
North CKGR & 32.2 & 25.8 & 100.0 & & & \\
Khutse & 36.8 & 32.7 & 37.2 & 100.0 & & \\
Mabuasehube & 22.1 & 21.2 & 29.2 & 52.9 & 100.0 & \\
Transfrontier & 15.5 & 13.9 & 22.2 & 36.1 & 54.5 & 100.0 \\
\cline { 2 - 5 } & \multicolumn{7}{c}{ Percentage similarity } \\
\end{tabular}

B. Species abundance structure (Steinhaus similarity x 100).

\begin{tabular}{lrrrrrr}
\hline Study area & Chobe & Savuti & CKGR & Khutse & Mabua. Transf. \\
\hline Chobe & 100.0 & & & & & \\
Savuti & 36.6 & 100.0 & & & & \\
North CKGR & 15.3 & 40.3 & 100.0 & & & \\
Khutse & 13.9 & 13.3 & 27.6 & 100.0 & & \\
Mabuasehube & 11.1 & 13.6 & 31.9 & 54.8 & 100.0 & \\
Transfrontier & 10.2 & 12.2 & 17.5 & 31.7 & 33.8 & 100.0 \\
\cline { 2 - 5 } & & \multicolumn{7}{c}{ Percentage similarity } \\
\hline
\end{tabular}




\section{Figure legends}

Fig. 1. Map showing the location of three study sites at each of six study areas within game reserves (= 18 study sites) relative to rainfall regimes across the Botswana Kalahari.

Fig. 2. Map showing the location of study sites and study areas relative to landscape types across the Botswana Kalahari as defined by Wit \& de Bekker (1990).

Fig. 3. Mean patterns of species richness (A, B), Shannon-Wiener diversity (C, D), abundance (E, F) and biomass $(\mathrm{G}, \mathrm{H})$ at six study areas (A, C, E, G) on five bait types (B, D, F, H) across the aridity gradient of the Botswana Kalahari with results for GLM factorial ANOVA and Tukey's HSD post-hoc tests in which different letters denote significant differences between data points $(P<0.05)$. Bait types are ordered according to perceived or measured degree of separation between their faunas (Tshikae et al. 2012b). Lines joining values for bait types are merely intended to guide the eye. Data recorded over $48 \mathrm{~h}$.

Fig. 4. Patterns of species richness at six study areas (A-F) on five bait types (G-K) across the aridity and mammal density gradient (L) of the Botswana Kalahari with results for GLM one-way ANOVA and Tukey's HSD post-hoc tests in which different letters denote significant differences between data points $(P<0.05)$. See notes on bait types in legend to Figure 3. Data recorded over $48 \mathrm{~h}$.

Fig. 5. Dendrogram showing patterns of overall similarity between dung beetle assemblage structure across the Botswana aridity gradient.

Fig. 6. Patterns of species loss to the northeast and southwest (A-C), and beta species diversity across the Botswana aridity gradient $(\mathrm{D}-\mathrm{F})$ comprising partitioning of overall beta diversity $\left(\beta_{\mathrm{cc}}\right)$ into species replacement $\left(\beta_{-3}\right)$ and species richness difference $\left(\beta_{\text {rich }}\right)$ components: A, D. Consecutive paired comparisons from NE to SW; B, E. Paired comparisons between Chobe and other study areas from NE to SW; C, F. Paired comparisons between Transfrontier and other study areas from SW to NE. 


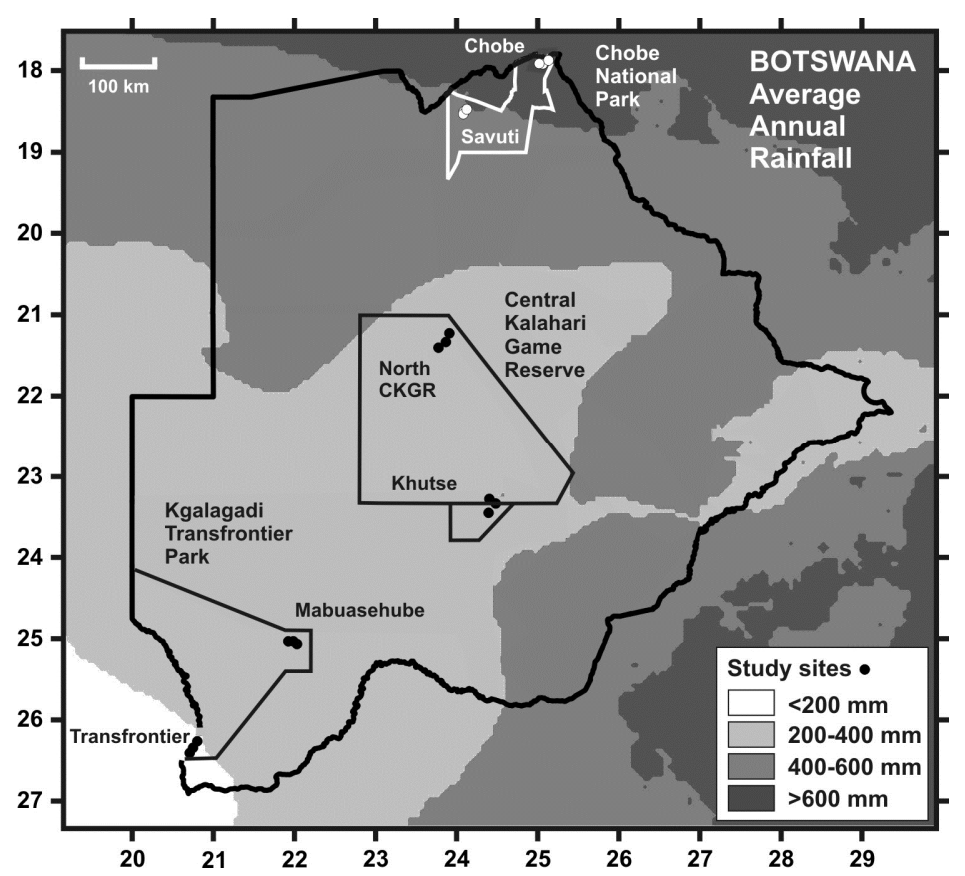

Figure 1

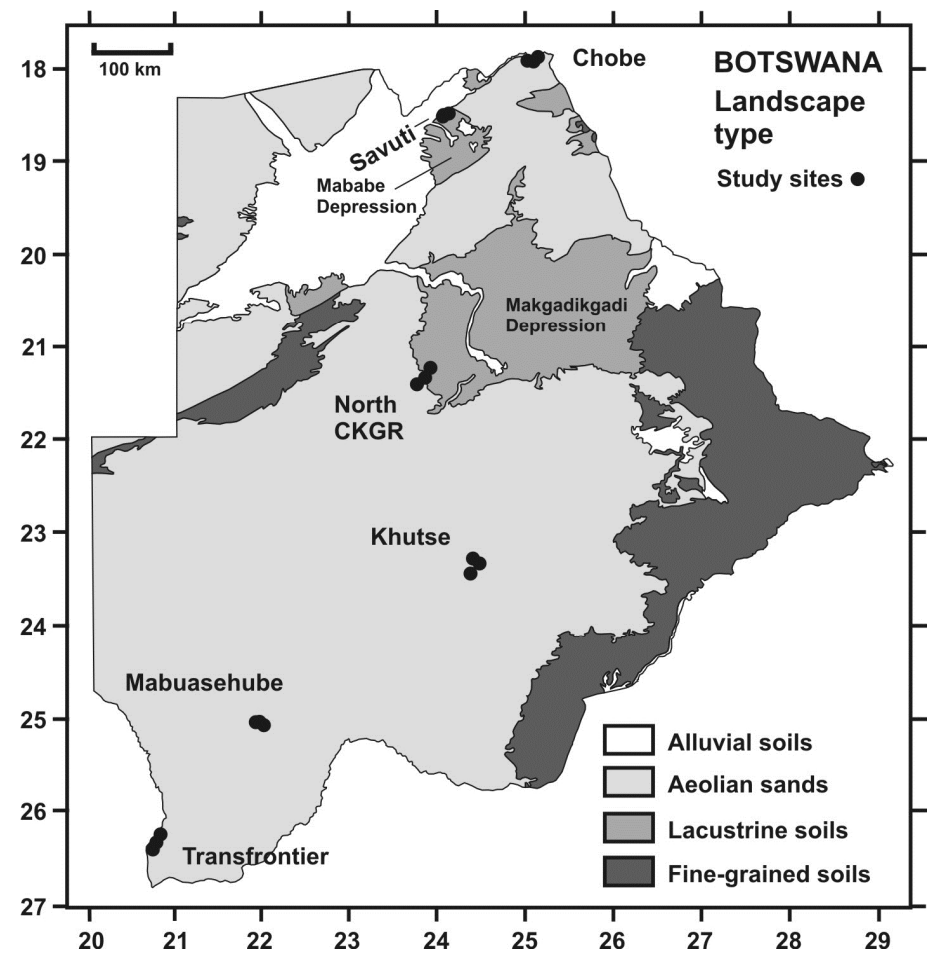

Figure 2 

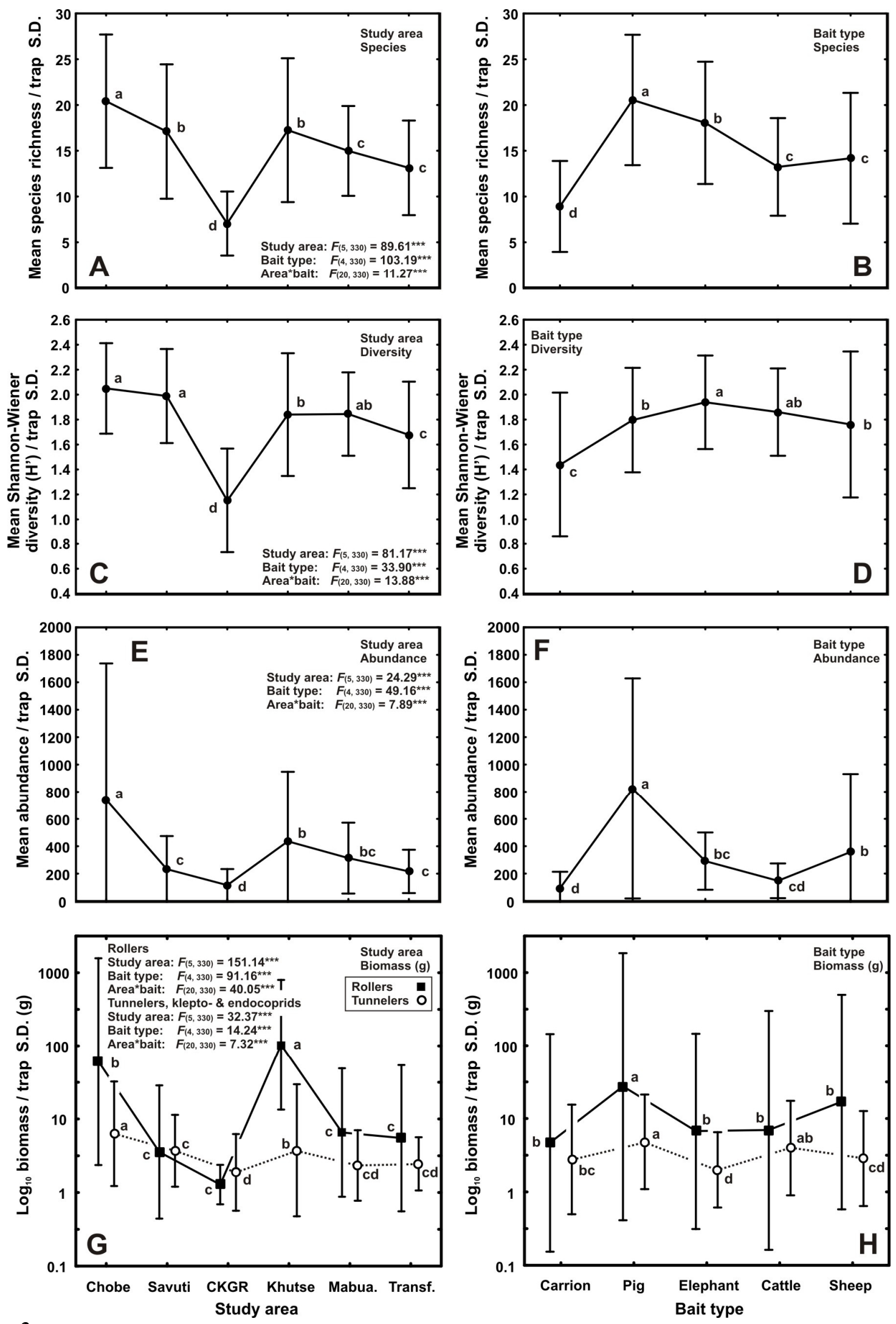

Figure 3 

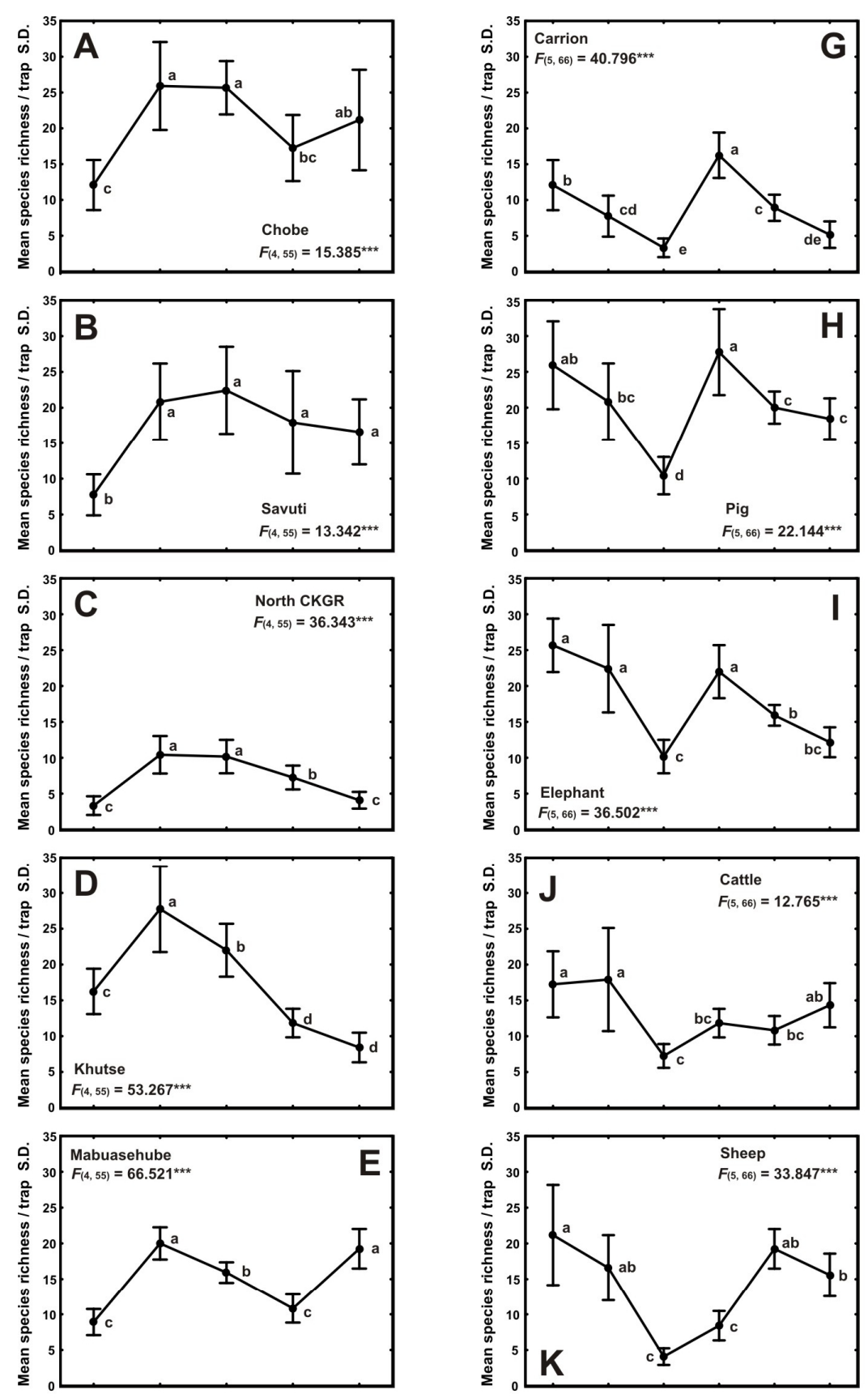

Figure 4
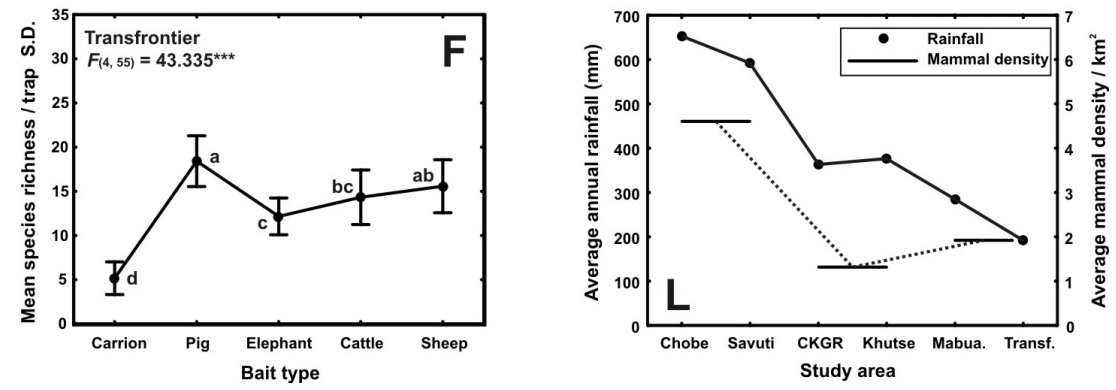


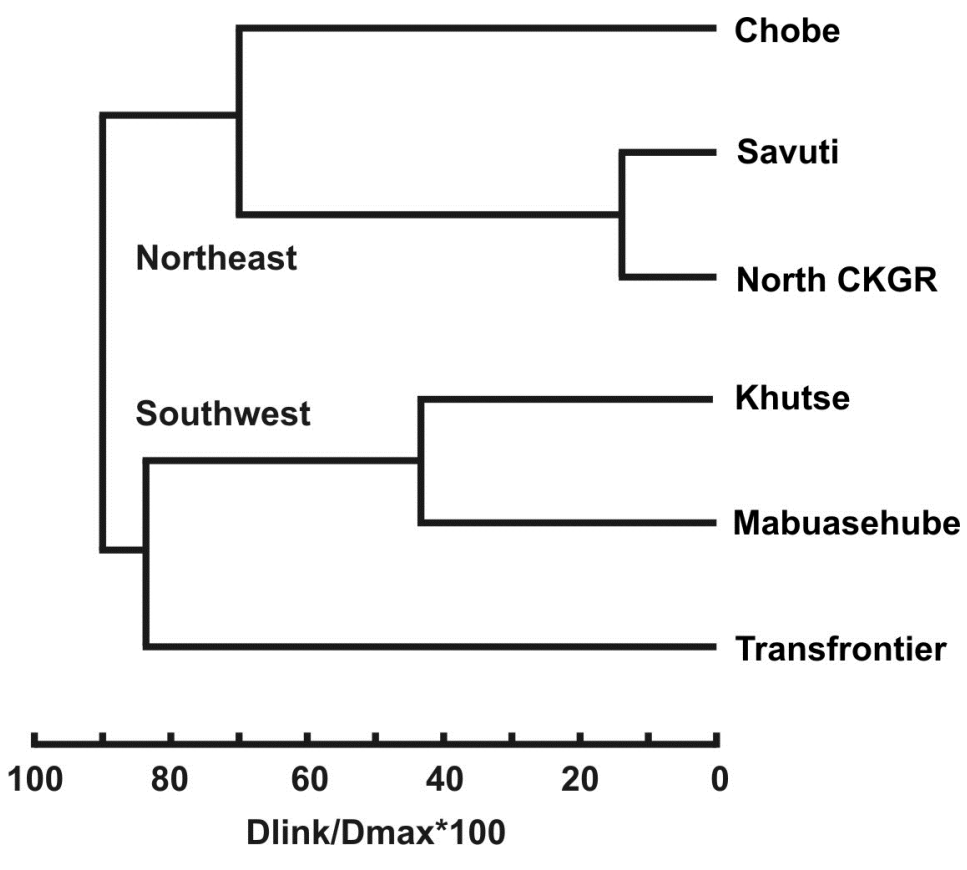

Figure 5. 

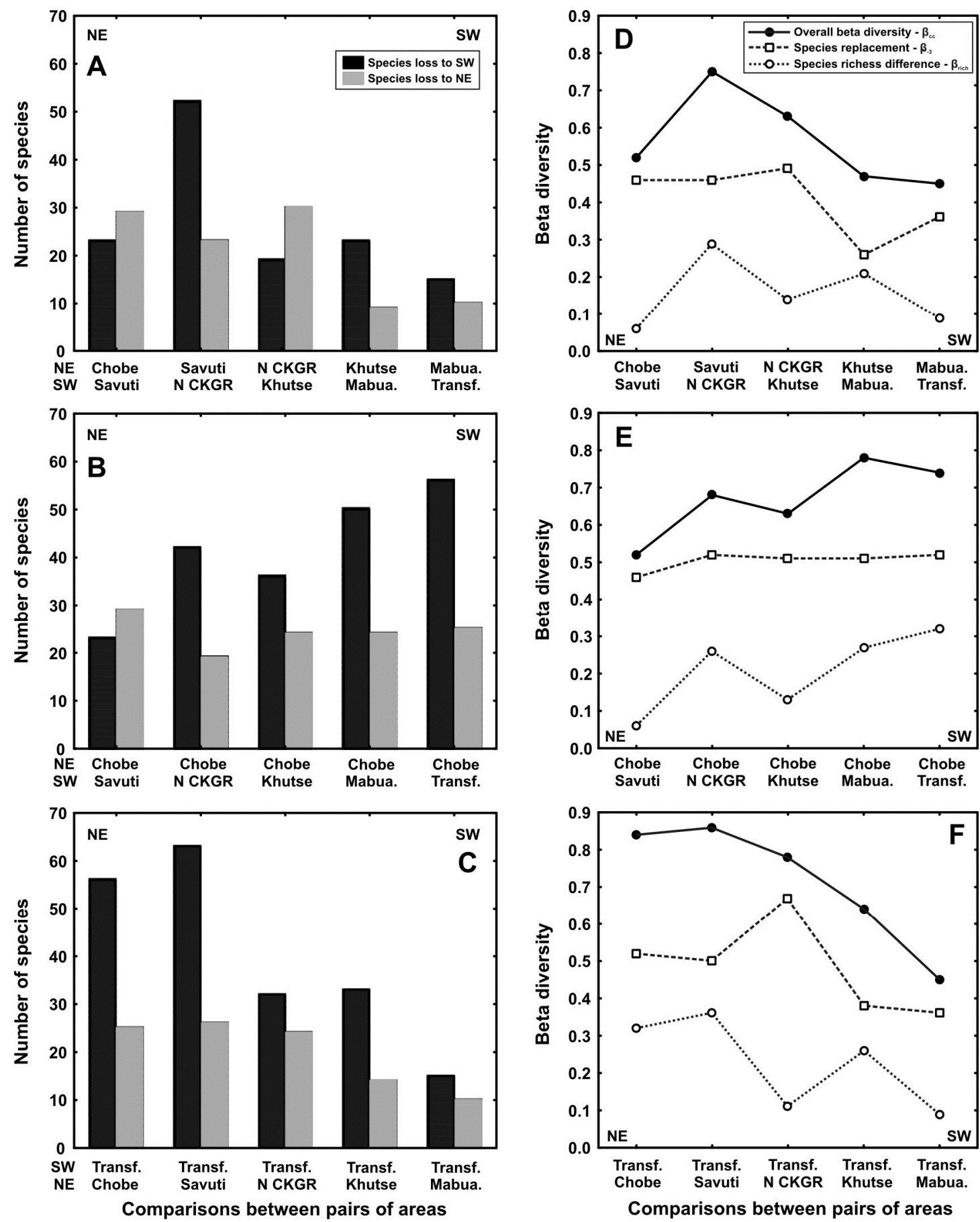

Figure 6. 